Phoey Lee Teh, Pei Boon Ooi \& Hew Gill, 2020. Relationships between emoticon usage and recipient groups in students' text messages. In Proceedings of the 22nd International Conference on Information Integration and Web-based Applications \& Services (iiWAS2020). ACM, New York, NY, USA, 5 pages. https://doi.org/10.1145/3428757.3429127

\title{
Relationships between emoticon usage and recipient groups in students' text messages
}

\author{
Phoey Lee Teh† \\ Department of Computing and \\ Information Systems, \\ School of Science and Technology \\ Sunway University, Selangor, \\ Malaysia \\ phoeyleet@sunway.edu.my
}

\begin{abstract}
Emoticons are pictographic representations of facial expressions that are used to convey emotions in text messages and other similar methods of communication. Most research on emoticons has examined how they are used in public forums rather than in private messaging. Using a sample of undergraduate students ( $\mathrm{n}=106$; male $52.83 \%$; mean age 20.26 years, SD 1.93 ), this study examines the use of emoticons in private text communication. Results reveal that emoticon usage is highest amongst friends, followed by siblings, then parents, other family members and more distant connections. Emoticons representing positive emotions are more commonly used than those representing strong negative emotions. Emoticons representing relief were found to be used particularly within peer group communication, whereas emoticons representing contentment were used more with family members and other, more distant, connections. The use of the "Relieved" emoticon with peers may reflect overcoming the stressors associated with shared educational challenges, whereas using the "Content" emoticon outside peers and family may represent emotional modulation and presentation.
\end{abstract}

\section{CCS CONCEPTS}

- Information Systems • Sentiment Analysis

\section{KEYWORDS}

Emoticons, Emotions, Facial expressions, Happy, Relieved

\section{ACM Reference format:}

Phoey Lee Teh, Pei Boon Ooi \& Hew Gill, 2020. Relationships between emoticon usage and recipient groups in students' text messages. In Proceedings of the 22nd International Conference on Information

Permission to make digital or hard copies of all or part of this work for personal or classroom use is granted without fee provided that copies are not made or distributed for profit or commercial advantage and that copies bear this notice and the full citation on the first page. Copyrights for components of this work owned by others than ACM must be honored. Abstracting with credit is permitted. To copy otherwise, or republish, to post on servers or to redistribute to lists, requires prior specific permission and/or a fee. Request permissions from Permissions@acm.org.

iiWAS '20, November 30-December 2, 2020, Chiang Mai, Thailand (C) 2020 Association for Computing Machinery. ACM ISBN 978-1-4503-89228/20/11..\$15.00 https://doi.org/10.1145/3428757.3429127

\author{
Colin M.H.D. Gill \\ Provost Office, Sunway \\ University, Selangor, Malaysia \\ hewg@sunway.edu.my
}

Integration and Web-based Applications \& Services (iiWAS2020). ACM New York, NY, USA, 5 pages. https://doi.org/10.1145/3428757.3429127

\section{Introduction}

Short message service (SMS) texts are charged per message, whereas Text Messaging Applications such as WhatsApp, LINE, and VIBER allow users to send messages free of charge, providing the users are connected to $\mathrm{Wi}-\mathrm{Fi}$ or subscribe to a data provider. The elimination of per message costs has precipitated a substantial increase in communication by instant messaging and a concomitant mushrooming of mobile messaging applications. Consequently, private messaging tools, such as WhatsApp, have become important in many areas of interpersonal communication, including for educational purposes [2][6][13] and in information dissemination and sharing in the arena of medical services [3].

Since the inception of Apple's first iPhone in 2007, there has been a compound annual growth rate of $18 \%$ in the smartphone market [21]. The development and evolution of messaging applications using smartphones have led to a corresponding growth in text messaging and the use of emoticons to enhance computer-mediated communication (CMC). Emoticons, Facemarks or Kaomoji [29] have become popular in virtual communication as a way to convey feelings and to indicate intended tone using representations of facial expressions [33]. Emoticons serve to fill the "expression gap" in non-face-to-face communication, and especially private messaging; and, over time, they have evolved into an effective, routine way to express emotions as a supplement to the text, or even as a complete alternative to traditional text-based communication [33]. The expression of feelings, opinions and points of view is often referred to as "sentiment" and the extraction of sentiment from non-verbal communication is referred to as sentiment analysis. Sentiment analysis has considerable economic value [1][17][43] and social value [42]. The increase in private messaging and in the use of emotions has led to a rapidly expanding library of emoticons, the sentiment of which is often far from obvious: successful sentiment analysis thus relies on a thorough understanding of emoticons and their different usage. The features and functions available in modern smart phones make it 
increasingly easy for users to convey their feelings through the use of emoticons. The consequent increasing use of emoticons in text messages, online feedback and in social media have greatly improved the potential to communicate (and for the miscommunication of) sentiment, thus opening up a useful resource in opinion mining [25].

With the advancement of social media and text messaging platforms, emoticons are being intensively utilised to express affection, opinion, support, and other emotions [26] or to demonstrate playfulness or jokes, and are, to a certain extent, replacing verbal communication [11]. Using emotions in Text Messaging may also help to promote relationship quality [27]. As emoticons have begun to play an increasingly significant role in online reviews and comments, organizations, businesses, and researchers have started to pay attention and study how emoticons are used [9][34]. Emoticons can enhance, reduce, change and add sentiment to a tweet [39]. Readers used emoticons to gauge the true feelings of online writers [20] and emoticons can even reverse the apparent sentiment value of textual comments [32]. More research was needed to explore the influence of different kinds of emoticons [9]; in this paper we investigate the use of emoticons in private text messages, an area largely neglected in the current literature, which focuses on usage in public forums.

\section{Emoticon and Emotion Works}

Sentiment is the embedded emotion, view or opinion expressed in text messaging and other non-verbal methods of communication. Many studies have focused on understanding the importance of emoticon use because they have the potential to provide a richer representative signal of sentiment than emotion words alone; consequently, tens or even hundreds of emoticons are being used every day, in their own unique ways, by authors in microblog environments [18] and elsewhere. For instance, the co-occurrence of emoticons offered a useful way to understand sentiment in microblogs [40]; [30] showed how a similar technique could be used to track changes in the collective mood expressed through social media before and after the 2011 Japan earthquake; and [34] showed that the contextual lens through which emoticon usage is viewed has a prominent impact on digital-based communication behaviours, and has important managerial implications. To better understand how to assess the emotional lexicon through emoticons we surveyed the current literature on the classification of emoticons and their associated emotions: the results are summarized in Table 1 .

Table 1: Classification of Emotions in Emoticon Research (2006 to 2018)

\begin{tabular}{|c|l|l|c|}
\hline $\begin{array}{c}\text { Ye } \\
\text { ar }\end{array}$ & $\begin{array}{l}\text { Sou } \\
\text { rce }\end{array}$ & Emotion Classification & $\begin{array}{c}\text { To } \\
\text { tal }\end{array}$ \\
\hline \multirow{2}{\infty}{} & {$[16]$} & $\begin{array}{l}\text { Angry, Annoyed, confused, disgusted, distress, } \\
\text { excited, frustrated, funny, grief, happy, laughing, } \\
\text { pain, tears, } \\
\text { upset. }\end{array}$ & 14 \\
\hline \multirow{\Xi}{\Xi}{} & {$[26]$} & $\begin{array}{l}\text { Anger, Anticipation, Disgust, Fear, Joy, Sadness, } \\
\text { Surprise, Trust } \\
\text { Anger, Disgust, Fear, Happiness, Sadness, } \\
\text { Surprise. }\end{array}$ & 8 \\
\hline$[5]$ & 6 \\
\hline
\end{tabular}

\begin{tabular}{|c|c|c|c|}
\hline$\stackrel{\stackrel{0}{\circ}}{a}$ & $\begin{array}{l}41] \\
{[31]}\end{array}$ & $\begin{array}{l}\text { Sadness, Joy, Surprise, Anger, Fear, Disgust. } \\
\text { Admiration, Amusement, Anger, Boredom, } \\
\text { Confidence, Curiosity, Desperation, Doubt, } \\
\text { Excitement, Exhaustion, Fascination, Fear, } \\
\text { Gratitude, Happiness, Hate, Hope, Indifference, } \\
\text { Inspiration,Longing,Love,Pride,Regret,Relaxed,S } \\
\text { adness,Shamed,Surprised, Sympathy. }\end{array}$ & $\begin{array}{l}6 \\
28\end{array}$ \\
\hline 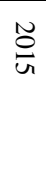 & [12] & $\begin{array}{l}\text { Admiration, Anger, Distress, Disappointment, } \\
\text { Disliking, Fear, Fears-confirmed, Gloating, } \\
\text { Gratitude, Gratification, Happy-for, Hope, Joy, } \\
\text { Liking, Pity, Pride, Reproach, Remorse, Relief, } \\
\text { Resentment, Shame, Satisfaction. }\end{array}$ & 22 \\
\hline$\underset{\sim}{\stackrel{O}{D}}$ & $\begin{array}{l}{[19]} \\
{[30]}\end{array}$ & $\begin{array}{l}\text { Anger, Contentment, Embarrassment, Interest, } \\
\text { Joy, Sadness, } \\
\text { Awful, Bad, Cool, Fun, Interesting, Scary }\end{array}$ & 6 \\
\hline \multirow[t]{2}{*}{$\underset{\omega}{\stackrel{0}{\sigma}}$} & $\begin{array}{l}{[39]} \\
{[14]}\end{array}$ & $\begin{array}{l}\text { Joy, Anger, Fear, Liking, Anger, Shame, Relief, } \\
\text { Sorrow, Excitement, Dislike, Surprise } \\
\text { Happiness, Boredom, Love, Sadness, Crying, } \\
\text { Embarrassment }\end{array}$ & $\begin{array}{l}11 \\
6\end{array}$ \\
\hline & $\begin{array}{l}37] \\
{[36]}\end{array}$ & $\begin{array}{l}\text { Joy, Anger, Excitement, Sadness, Liking, Fear, } \\
\text { Relief, Dislike, Surprise, Shyness. } \\
\text { Happiness, Surprise, Fear, Sadness, Disgust, } \\
\text { Anger }\end{array}$ & $\begin{array}{l}10 \\
6\end{array}$ \\
\hline$\stackrel{N}{\stackrel{N}{N}}$ & $\begin{array}{l}{[24]} \\
{[10]}\end{array}$ & $\begin{array}{l}\text { Happy, Fear, Sad, Surprise, Disgust, Anger } \\
\text { Happy, Sad, Winking, Cheeky, Laughing, } \\
\text { Shocked, Worried, Hug, Angry, Serious }\end{array}$ & $\begin{array}{l}6 \\
10\end{array}$ \\
\hline$\underset{\infty}{\mathbb{8}}$ & [35] & $\begin{array}{l}\text { Neutral, Surprise, Happiness, Anger, Disgust, } \\
\text { Anger }\end{array}$ & 6 \\
\hline 产 & {$[42]$} & Happy, Sad, Angry, Surprise & 4 \\
\hline
\end{tabular}

Examination of Table 1 shows the emoticons have been classified in 4 to as many as 28 different categories; most commonly between six and eleven categories. We categories emoticons into one of eleven different categories (Table 2), but use only ten of them: emoticons of "uncategorized" were ignored.

Emotional displays where the message sender is known to the receiver are influenced by the familiarity of the intended message recipient [4] and also by various cultural factors, with some evidence that Asians tend to modulate and attenuate their emotional displays more than Westerners across different situations [28]. When such factors are considered together this may explain why context appears to affect emoticon usage more than personal variables such as gender [15][38], age [22][23] or nationality [10][22] and explains why emoticons tend to be used less in formal contexts [8] or categorized as electronic dialect [22]. Emoticons use is also known to be greater in communication between friends than between strangers, and more in positive contexts than negative ones [7][23]. Further exploring the ways in which emoticons are used in messages directed between individuals who are known to each other is timely, and potentially fruitful line of enquiry. The present study seeks to address the paucity of data in personal messaging environments by investigating how recipient relationships in a university context may affect the number and types of emoticons used in private messaging, and whether or not there is any relationship between these variables. 
Relationships between emoticon usage and recipient groups in students' text messages

\section{Methods}

A total of 115 undergraduate students who are routine WhatsApp users were recruited for the present research by inviting them through social media to access a website introducing the project and explaining its purpose. Those who chose to participate gave their informed consent before proceeding to complete a form recording basic demographic information and then filling out a brief survey about various aspects of their emoticon usage. The survey asked participants how often they used emoticons in WhatsApp messages, and then asked them to rate how frequently they used emoticons from each of the first ten emotional categories shown in Table 2. Ratings use a five-point verbally anchored Likert scale ranging from 1 - Never Use through 3 - Sometimes to 5 - Frequently Used. Participants were then asked to rate how frequently they used emoticons when communicating with various types of recipient. Data was analysed by using SPSS. Of all participants, nine were non-Malaysian or did not declare their nationality: data from these participants were excluded from the analysis, leaving a sample of 106 participants, of which 52.83 percent were male. The mean age was 20.26 (SD 1.93).

Table 2: WhatsApp Default Emoticon Selection Classified by Emotional Category

\begin{tabular}{|c|c|c|}
\hline Emotional Category & No & Emoticons \\
\hline $\begin{array}{l}\text { Positive Affect (Happiness /Joy/ } \\
\text { Interest/Liking/Excitement/Love) }\end{array}$ & 8 & 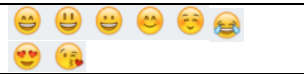 \\
\hline $\begin{array}{l}\text { Negative Affect } \\
\text { (Sadness/Sorrow/Dislike/Shame/ } \\
\text { Crying) }\end{array}$ & 5 & 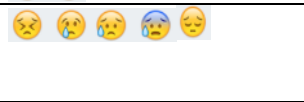 \\
\hline Anger & 4 & (20) (2) है \\
\hline Surprise & 5 & $\because \because \because \because 2$ \\
\hline Fear & 3 & (25) 62 \\
\hline Disgust & 2 & $\because \Leftrightarrow$ \\
\hline Neutral/Boredom & 7 & $\Leftrightarrow \because \because \because \because \Theta \because$ \\
\hline Embarrassment & 1 & 상 \\
\hline Contentment & 5 & 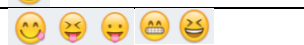 \\
\hline Relief & 4 & (2x) $\Leftrightarrow \theta$ \\
\hline Uncategorized & 7 & (20) (1) (1) \\
\hline
\end{tabular}

\section{Results and Discussion}

The frequency of emoticon Usage by Participants is given in Table 3 . Eighty percent of respondents used emoticons regularly in their messaging.

Table 3: Participants' Usage of Emoticons in Messaging ( $N=106)$

\begin{tabular}{|l|l|l|l|l|l|}
\hline Items & Freq & $\%$ & Items & Freq & $\%$ \\
\hline Never & 0 & 0.0 & Often & 21 & 19.8 \\
\hline Rarely & 3 & 2.8 & Usually & 27 & 25.5 \\
\hline Occasionally & 6 & 5.7 & Always & 36 & 34.0 \\
\hline Sometimes & 13 & 12.3 & & & \\
\hline
\end{tabular}

\subsection{Does the Amount of Emoticon Usage Vary by Type of} Emoticon?

The first section of the survey yielded counts of how often emoticons in each of the 10 used categories shown in Table 3 were used by participants in their messaging. A repeated measure analysis of variance (ANOVA) with a Greenhouse-Geisser
iiWAS2020, August, 2020, Chiangmai, Thailand

correction was deployed to assess if there were any significant differences in the usage of these categories of emoticon, and the result showed that mean emoticon usage did differ significantly by type of emoticon $(\mathrm{F}(6.928,727.476)=19.62, p<.001)$. Post hoc tests using the Bonferroni correction showed that there were some significant pairwise differences in usage between the different types of emoticon as shown in Figure 1.

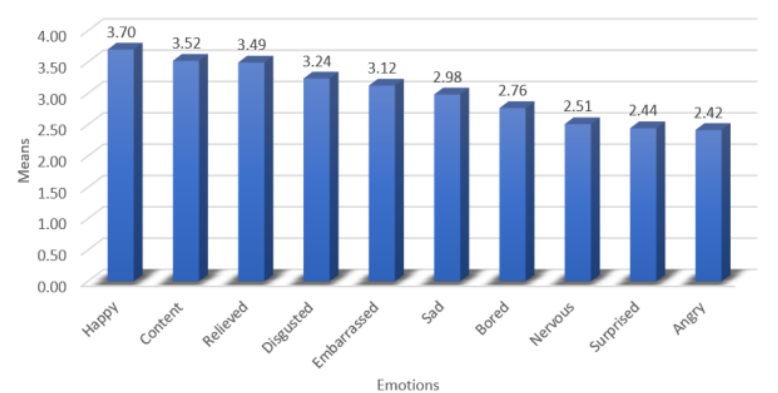

Figure 1: Mean Levels of Emoticon Usage by Emoticon Type Figure 1 and Table 4 shows that emoticons representing positive emotions - Happy, Content and Relieved - were used at similar levels to each other, and were significantly more commonly used than those emoticons relating to the emotions of Sad, Angry, Surprise, Embarrass, Bored and Nervous. Within this latter group, Sad, Disgust and Embarrassed emoticons were used more frequently than the less-ambivalent Angry, Surprise, Bored and Nervous.

Table 4: Significant Pairwise Differences in Emoticon Usage

\begin{tabular}{|c|c|c|c|c|c|c|c|c|c|}
\hline 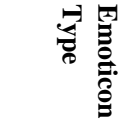 & 尽 & ¿̊ & 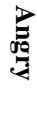 & & $\frac{\pi}{\frac{0}{0}}$ & 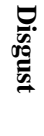 & 졸 & $\begin{array}{l}\text { ర్రా } \\
2 \\
2\end{array}$ & 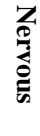 \\
\hline Happy & ns & $* *$ & ** & $* *$ & ns & ns & $*$ & $* *$ & ** \\
\hline Contented & & $*$ & $* *$ & $* *$ & ns & ns & ns & $* *$ & $* *$ \\
\hline Sad & & & $* *$ & $* *$ & $*$ & ns & ns & ns & * \\
\hline Angry & & & & ns & $* *$ & $* *$ & $* *$ & ns & $\mathrm{ns}$ \\
\hline Surprise & & & & & $* *$ & $* *$ & $* *$ & ns & ns \\
\hline Relieved & & & & & & ns & ns & $* *$ & $* *$ \\
\hline Disgust & & & & & & & ns & ns & $* *$ \\
\hline Embarrass & & & & & & & & ns & $* *$ \\
\hline Bored & & & & & & & & & ns \\
\hline
\end{tabular}

4.2 Does the Amount of Emoticon Usage Vary Depending on the Recipient of the Text?

The frequencies of emoticon usage in messages to specific groups of recipients were compared using a repeated measure analysis of variance (ANOVA) with a Greenhouse-Geisser correction which showed that mean emoticon usage differed significantly between the recipient types, $\mathrm{F}(4.354,457.146)=59.348, p<.001$.

Post hoc tests using the Bonferroni correction showed that there were several significant pairwise differences in emoticon usage between the different recipient types, as shown in Table 5 and Figure 2. Highest emoticon usage was with Friends and Boy/Girl Friends, and emoticon usage with these two types of recipients was 
significantly higher than usage with any other recipient type. Emoticon usage within the family was significantly higher for siblings than other relatives and parents, with these latter two recipient types being similar with "Others", outside the immediate family. Emoticon usage with lecturers was significantly lower than with every other recipient type.

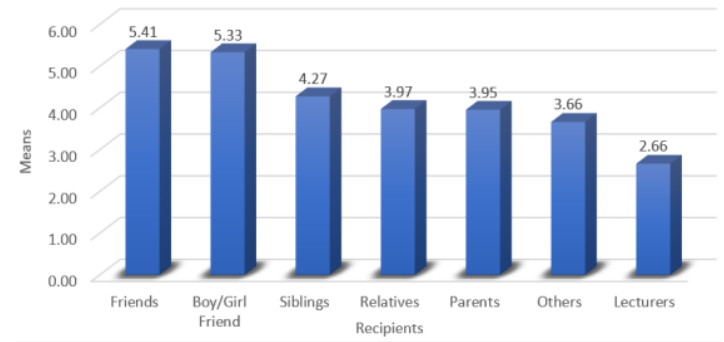

Figure 2: Mean Levels of Emoticon Usage by Message Recipient

Table 5: Differences in Emoticon Usage Across Recipient Groups

\begin{tabular}{|c|c|c|c|c|c|c|}
\hline Recipient & 串 & 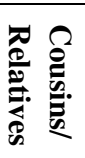 & 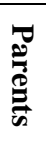 & 离 & 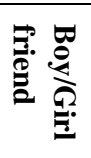 & 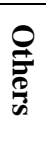 \\
\hline Friend & $* *$ & $* *$ & $* *$ & $* *$ & $\mathrm{~ns}$ & $* *$ \\
\hline Siblings & & * & $*$ & $* *$ & $* *$ & $* *$ \\
\hline Cousins/ Relatives & & & ns & $* *$ & $* *$ & ns \\
\hline Parents & & & & $* *$ & $* *$ & $* *$ \\
\hline Lecturers & & & & & $* *$ & $* *$ \\
\hline $\begin{array}{l}\text { Boy/ } \\
\text { Girlfriend }\end{array}$ & & & & & & $* *$ \\
\hline
\end{tabular}

4.3 Are Particular Types of Emoticons Used with Particular Recipient Groups?

In order to assess the extent to which particular emoticons might be used with particular types of the recipient, the Pearson productmoment correlation coefficients between reported emoticon use and frequency of using emoticons in messages to particular recipients were computed. Given that this exercise was investigative rather than predictive a conservative Bonferroni correction was applied to ensure parsimony in the identification of potentially significant relationships, so only correlation coefficients with a probability $\leq 0.0007$ were deemed worthy of interest. Only three correlations met this stringent criterion Relieved + Friends $(r=.499, p<.0001)$, Relieved + Boy/Girl Friends $(r=.422, p<.0001)$ and Content + Others $(r=.332, p<.0005)$. This suggested that higher levels of messaging to Friends and Boy/Girl Friends was associated with higher usage of the Relieved emoticon and that levels of messaging to Others was associated with higher usage of the Content emoticon.

Drawing upon the research briefly considered at the outset, the finding that participants used emoticons most with friends, boy/girlfriends and siblings, then with family members and others, and least with lecturers is broadly what would have been expected in light of the findings reported by [7][23]. That emoticon usage is found to be greatest in informal and positive contexts involving friends, appears to offer some support for the position adopted by
$[10][[22]$ that context is the most important predictor of emoticon usage.

However, the split between friends and siblings, and other family members suggests that more than just the informal and intimate context of the massagers-recipient relationship shapes emoticon usage. It is possible that the split between peers and other family members arises because participants were modulating their emotional displays (via emoticon use) for their parents in ways that would be predicted from studies of emotional displays in Asia: comparing Japan with Canada and the USA [28]. This might also explain why there was no significant difference in emoticon usage within the family as compared to other people outside the family, despite the clear differences that this would imply for the context of communication. The differences between friends and siblings versus the combination of immediate family with other people may indicate that expression via emoticons is a function of not just intimacy, but also age-relatedness and a certain amount of impression management or emotional modulation of the type that can be expected when young adults deal with older ones [4].

Another significant association identified in this research is that of higher levels of "Relieved" emoticon usage when messaging immediate friends, as compared to, for example, family members. It may be related to the levels of shared experience (e.g. a just completed examination or assignment) and/or with relationship moderated levels of emotional candor. More work is necessary before any firm conclusions can be drawn on this association.

\section{Conclusion and Recommendation}

This preliminary study has identified two significant factors, namely that (i) Emoticon usage is greater in less formal settings; and (ii) that the use of the "relieved" emoticon is much higher between intimate friends than other groups. This research is based on a small cohort of Asian (Malaysian) students and we are now extending this work to include larger cohort sizes and a broader section of people namely, age-, and socio-economic and cultural background. Never-the-less this research has shown that difference exist between emoticon use in private and open messaging environments and that there is rich potential for future research on emoticon usage in private social media communication.

\section{References}

[1] AbdelFattah, M., Galal, D., Hassan, N., Elzanfaly, D., \& Tallent, G. 2017. A sentiment analysis tool for determining the promotional success of fashion images on Instagram. International Journal of Interactive Mobile Technologies (iJIM), 11(2), 66-73.

[2] Aljaad, M., \& Hamad, N. 2017. Whatsapp for educational purposes for female students at College of Education-King Saud University. Education, 137(3), 344-366.

[3] Bakshi, S. G., \& Bhawalkar, P. 2017. Role of WhatsApp-based discussions in improving residents' knowledge of post-operative pain management: a pilot study. Korean journal of anesthesiology, 70(5), 542 .

[4] Camras, L. A., Shuster, M. M., \& Fraumeni, B. R. 2014. Emotion socialization in the family with an emphasis on culture. In Children and emotion (Vol. 26, pp. 67-80). Karger Publishers.

[5] Chen, Y. L., Chang, C. L., \& Yeh, C. S. 2017. Emotion classification of YouTube videos. Decision Support Systems, $101,40-50$.

[6] Dar, Q. A., Ahmad, F., Ramzan, M., Khan, S. H., Ramzan, K., Ahmed, W., \& Kamal, Z. 2017. Use of social media tool 
Relationships between emoticon usage and recipient groups in students' text messages

"Whatsapp" in medical education. Annals of King Edward Medical University, 23(1).

[7] Derks, D., Bos, A. E., \& Von Grumbkow, J. 2008. Emoticons in computer-mediated communication: Social motives and social context. Cyberpsychology \& behavior, 11(1), 99-101.

[8] Derks, D., Fischer, A. H., \& Bos, A. E. 2008. The role of emotion in computer-mediated communication: A review. Computers in Human Behavior, 24(3), 766-785.

[9] Duan, J., Xia, X., \& Van Swol, L. M. 2018. Emoticons' influence on advice taking. Computers in Human Behavior, 79, 53-58.

[10] Fullwood, C., Orchard, L. J., \& Floyd, S. A. 2013. Emoticon convergence in Internet chat rooms. Social Semiotics, 23(5), 648-662.

[11] Ganster, T., Eimler, S. C., \& Krämer, N. C. 2012. Same same but different!? The differential influence of smilies and emoticons on person perception. Cyberpsychology, Behavior, and Social Networking, 15(4), 226-230.

[12] Gao, K., Xu, H., \& Wang, J. 2015. A rule-based approach to emotion cause detection for Chinese micro-blogs. Expert Systems with Applications, 42(9), 4517-4528.

[13] Goyal, A., Tanveer, N., \& Sharma, P. 2017. WhatsApp for teaching pathology postgraduates: a pilot study. Journal of pathology informatics, 8 .

[14] Hogenboom, A., Bal, D., Frasincar, F., Bal, M., de Jong, F., \& Kaymak, U. 2013. Exploiting emoticons in sentiment analysis. Proceedings of SAC'13, the 28th Annual ACM Symposium on Applied Computing (pp. 703-710). ACM New York, NY, USA 2013. https://doi.org/10.1145/2480362.2480498

[15] Hudson, M. B., Nicolas, S. C., Howser, M. E., Lipsett, K. E., Robinson, I. W., Pope, L. J., Hobby, A. F., \& Friedman, D. R. 2015. Examining how gender and emoticons influence Facebook jealousy. Cyberpsychology, Behavior, and Social Networking, 18(2), 87-92.

[16] Jaeger, S. R., Roigard, C. M., \& Ares, G. 2018. Measuring consumers' product associations with emoji and emotion word questionnaires: case studies with tasted foods and written stimuli. Food Research International, 111(Feb), 732-747.

[17] Jang, H.-J., Sim, J., Lee, Y., \& Kwon, O. 2013. Deep sentiment analysis: Mining the causality between personality-valueattitude for analyzing business ads in social media. Expert Systems with applications, 40(18), 7492-7503.

[18] Jiang, F., Liu, Y.-Q., Sun, H.-B. L.-S., Zhu, X., Zhang, M., \& Ma, S.-P. 2015. 利用表情符空间进行微博情感分析. 计算机 科学技术学报, 30(5), 1120-1129. https://doi.org/https://doi.org/10.1007/s11390-015-1587-1

[19] Lee. T.P., Wong. R. Ismail S. 2014. Emotion Determination Template on Facebook to Justify Emotional Level. International Journal of Innovation, Management and Technology, 5(1), 3942. https://doi.org/10.7763/ijimt.2014.v5.483

[20] Mahajan, C., \& Mulay, P. 2015. E3: effective emoticon extractor for behavior analysis from social media. Procedia Computer Science, $\quad 50,610-616$. https://doi.org/https://doi.org/10.1016/j.procs.2015.04.093

[21] O'Dea, S. 2020. Market share of mobile device vendors in the United Kingdom (UK) 2010-2019. Retrieved March 14 from https://www.statista.com/statistics/487780/market-share-ofmobile-device-vendors-uk/

[22] Oleszkiewicz, A., Karwowski, M., Pisanski, K., Sorokowski, P., Sobrado, B., \& Sorokowska, A. 2017. Who uses emoticons? Data from 86702 Facebook users. Personality and individual differences, 119, 289-295.

[23] Prada, M., Rodrigues, D. L., Garrido, M. V., Lopes, D., Cavalheiro, B., \& Gaspar, R. 2018. Motives, frequency and attitudes toward emoji and emoticon use. Telematics and Informatics, 35(7), 1925-1934.

[24] Purver, M., \& Battersby, S. 2012. Experimenting with Distant Supervision for Emotion Classification. In Proceedings of the
iiWAS2020, August, 2020, Chiangmai, Thailand

13th Conference of the European Chapter of the Association for Computational Linguistics. 482-491.

[25] Rathan, M., Hulipalled, V. R., Venugopal, K., \& Patnaik, L. 2018. Consumer insight mining: Aspect based Twitter opinion mining of mobile phone reviews. Applied Soft Computing, 68, 765-773.

[26] Riordan, M. A. 2017. The communicative role of non-face emojis: Affect and disambiguation. Computers in Human Behavior, 76, 75-86.

[27] Rodrigues, D., Lopes, D., Prada, M., Thompson, D., \& Garrido, M. V. 2017. A frown emoji can be worth a thousand words: Perceptions of emoji use in text messages exchanged between romantic partners. Telematics and Informatics, 34(8), 15321543.

[28] Safdar, S., Friedlmeier, W., Matsumoto, D., Yoo, S. H., Kwantes, C. T., Kakai, H., \& Shigemasu, E. 2009. Variations of emotional display rules within and across cultures: A comparison between Canada, USA, and Japan. Canadian Journal of Behavioural Science/Revue canadienne des sciences du comportement, 41(1), 1.

[29] Sakai, N. 2018. Social differences in CMC: a case study of Japanese mobile phone e-mail. Journal of Technology in Behavioral Science, 3(3), 190-205.

[30] Sasahara, K. 2014. Quantifying collective mood by emoticon networks. Proceedings of the 2014 ACM conference on Web science. https://doi.org/10.1145/2615569.2615658

[31] Suet, J., \& Liew, Y. 2016. Fine-Grained Emotion Detection in Microblog Text. Retrieved https://surface.syr.edu/etd/440

[32] Teh P.L., Rayson P., Pak I., Piao S., Yeng S.M. 2016. Reversing the Polarity with Emoticons. In: Métais E., Meziane F., Saraee M., Sugumaran V., Vadera S. (eds) Natural Language Processing and Information Systems. NLDB 2016. Lecture Notes in Computer Science, vol 9612. Springer, Cham. https://doi.org/10.1007/978-3-319-41754-7_48

[33] Troiano, G., \& Nante, N. 2018. Emoji: what does the scientific literature say about them?-A new way to communicate in the 21th century. Journal of Human Behavior in the Social Environment, 28(4), 528-533.

[34] Tseng, T. H., \& Hsieh, S. H. 2019. Determinants of emoticon usage in mobile instant messaging: A construal level theory perspective. Behaviour \& Information Technology, 38(3), 289301.

[35] Tsihrintzis, G. a., Virvou, M., Stathopoulou, I.-O., \& Alepis, E. 2008. On Improving Visual-Facial Emotion Recognition with Audio-lingual and Keyboard Stroke Pattern Information. In 2008 IEEE/WIC/ACM International Conference on Web Intelligence and Intelligent Agent Technology 810-816. IEEE Computer Society. https://doi.org/10.1109/WIIAT.2008.282.

[36] Ulinski, M., Soto, V., \& Hirschberg, J. 2012. Finding emotion in image descriptions. Proceedings of the First International Workshop on Issues of Sentiment Discovery and Opinion Mining - WISDOM '12, 1-7. https://doi.org/10.1145/2346676.2346684

[37] Urabe, Y., Rzepka, R., \& Araki, K. 2013. Emoticon Recommendation System for Effective Communication. 1460 1461. Proceedings of the 2013 IEEE/ACM International Conference on Advances in Social Networks Analysis and Mining.

[38] Wolf, A. 2000. Emotional expression online: Gender differences in emoticon use. Cyberpsychology \& behavior, 3(5), 827-833.

[39] Yamamoto, Y., Kumamoto, T., \& Nadamoto, A. 2014. Role of emoticons for multidimensional sentiment analysis of Twitter. Proceedings of the 16th International Conference on Information Integration and Web-based Applications \& Services, https://doi.org/10.1145/2684200.2684283

[40] Yamashita, R., Yamaguchi, S., \& Takami, K. 2010. A method 
of inferring the preferences and mood of mobile phone users by analyzing pictograms and emoticons used in their emails. 2010

Third International Conference on Advances in Human-

Oriented and Personalized Mechanisms, Technologies and Services.

[41] Yasmina, D., Hajar, M., \& Hassan, A. M. 2016. Using YouTube Comments for Text-based Emotion Recognition. Procedia Computer Science, 83(Ant), 292-299. https://doi.org/10.1016/j.procs.2016.04.128.

[42] Yuasa, M., Saito, K., \& Mukawa, N. 2006. Emoticons Convey Emotions without Cognition of Faces : An fMRI Study. In CHI'06 extended abstracts on Human Factors in Computing Systems. 1565-1570.

[43] Yu, Y., Duan, W., \& Cao, Q. 2013. The impact of social and conventional media on firm equity value: A sentiment analysis approach. Decision support systems, 55(4), 919-926. https://doi.org/https://doi.org/10.1016/j.dss.2012.12.028. 